\title{
A SLOUGHING FIBROID OF UTERUS WHICH RUPTURED THROUGH THE FUNDUS INTO THE PERITONEAL CAVITY, CAUSING GENERAL PERITONITIS. LAPAROTOMY-COMPLETE HYSTERECTOMY.
}

\author{
By HAMILTON DRUMIOND, Newcastle-ox-TyNe.
}

Turs case appears worthy of record, as it illustrates an extremely rare complication of a uterine fibroid.

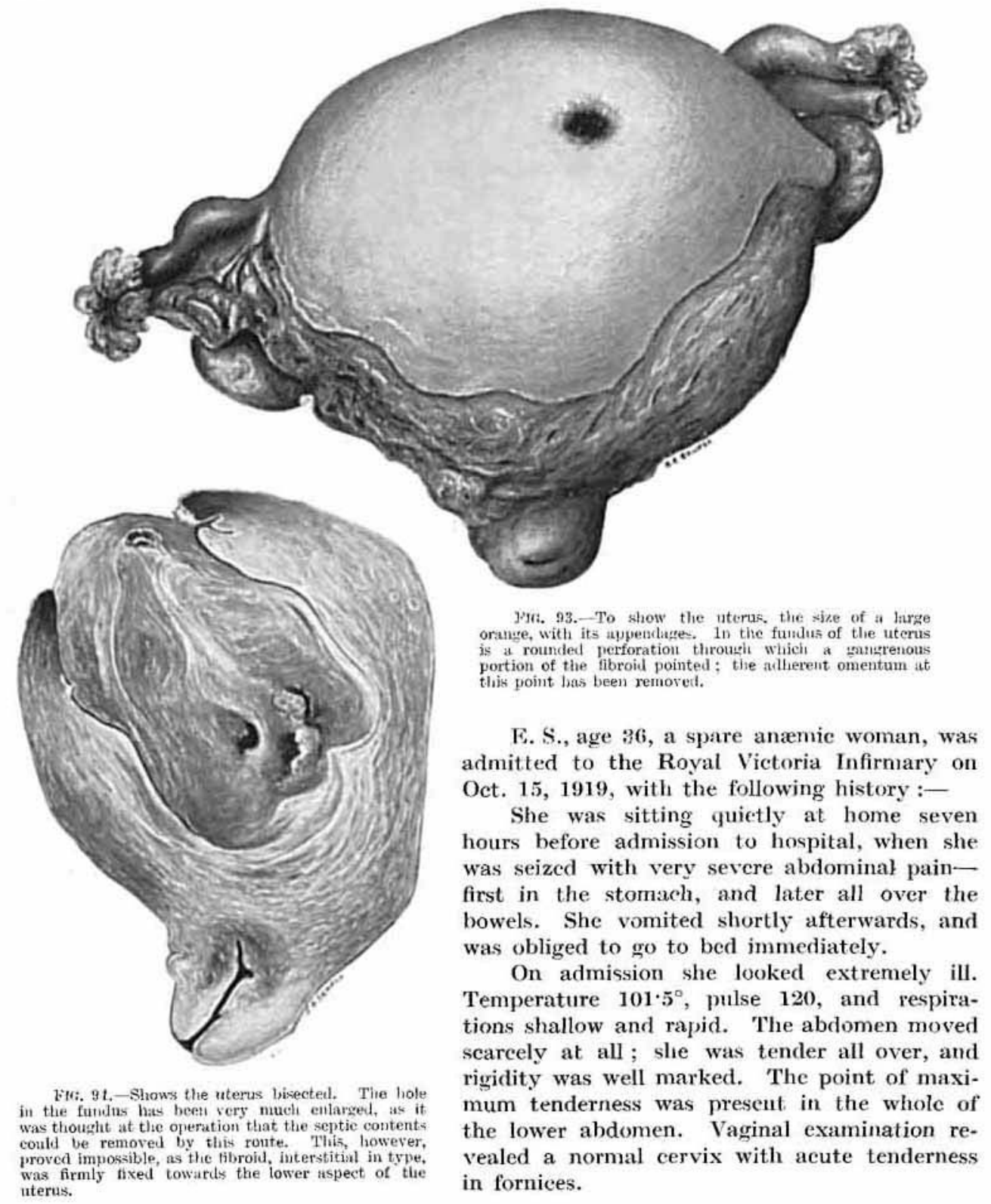




\title{
142 THE BRITISH JOURNAL OF SURGERY
}

Her previous history showed that she had been married ten years; one child nine years ago, healthy; and a miscarriage eight years ago. For the last two years she has suffered from menorrhagia, blood coming away every fortnight, often in large quantities and in clots. She was thought to have a leaking pyosalpynx, but the sudden onset of her pain suggested rupture of some other viscus.

Operation eight hours after her sudden attack. Open ether. Mid-line incision below umbilicus. The peritoneal cavity was found to contain a large amount of free turbid fluid not unlike that seen in ruptured gastric ulcer. About two pints were mopped out of the lower abdomen. The omentum was found to be adherent to the fundus of the uterus ; on separating the adhesions, a hole the size of a lead-pencil bore was seen entering the uterine cavity. On enlarging the hole in the uterus a very offensive smell was noticed, with escape of thick pus, and the upper surface of a sloughing fibroid was seen, and felt with the finger. The tumour was very firmly fixed in the cavity of the uterus.

The most rational treatment appeared to be the removal of the focus. The uterus was removed by supravaginal hysterectomy, including the cervix and both tubes and ovaries. A drain of gauze was inserted into the vagina for five days, and the abdominal wound was drained by a rubber tube for forty-eight hours.

Recovery was straightforward, and she returned home three weeks after operation.

\section{DIVISION OF POSTERIOR SPINAL ROOTS FOR THE RELIEF OF PAIN DUE TO COMPlete disRuption of THE BRachial PleXus.}

\author{
By Sir. H. GIIBERT BARLiNg, Birmingham.
}

TrE patient, an officer, was wounded early in 1915, the injuries sustained being severe compound fracture of the right clavicle, with division of the subclavian vessels, complete disruption of the brachial plexus, and injury to the upper part of the right thorax involving the lung. He passed through a perilous time, and it was owing to the skilful. care of Mr. Kempe, of Salisbury, that his life was saved.

I did not see the patient until April, 1916, when I found the following conditions. The right arm was enormously swollen, and of course quite helpless and anæsthetic. The wound was healed, except that there was a bronchial sinus opening to the upper part of the right lung.

For about a year the patient had suffered intolerable pain referred to the distribution of the brachial plexus, pain which made life an absolute burden, and for which increasing doses of morphia had been required, although the patient, knowing the drawbacks of the remedy, had done his best to do with as little morphia as possible.

His condition when I saw him was pitiable, and he was an absolute wreck physically. I came to the conclusion that cicatrization of the wound with involvement of the proximal end of the divided nerves was responsible for the pain, and that, owing to the tremendous extent of the cicatrization at the root of the neck, it was little likely that successful operation locally, for freeing and shortening the divided nerves, could be performed. I therefore advised intrathecal division of the posterior roots of the brachial plexus on the right side, though one could not but feel that the operation was accompanied by considerable risk from shock and from possible infection, owing to the existing bronchial sinus not far from the incision. If the operation was successfully accomplished, it was arranged that amputation of the disabled limb should follow when the patient was fit to bear it.

The operation was performed on April 11, 1916, with the assistance of Mr. Kempe. A little adrenalin was injected into the tissues first of all.

It is not necessary to enter into the details of the operation, except to say that no attempt was made to deal with the roots through a hemilateral laminectomy, nor through the unopened theca. A partial resection of lamina does not give sufficient room to work 